\title{
Thin Layer Chromatography for Some Derivatives of 1,4-Naphthoquinone
}

\author{
Ihor Poliuzhyn, Oksana Smirnova, Yosyp Yatchyshyn \\ Department of Physical, Analytical and General Chemistry, Lviv Polytechnic National University, \\ UKRAINE, Lviv, S. Bandera Street 12, E-mail: ihor.p.poliuzhyn@lpnu.ua
}

\begin{abstract}
The chromatographic characteristics are investigated for six derivatives of 1,4naphthoquinone under conditions of normal-phase thin-layer chromatography for benzene-based binary eluent and such enhancing polar solvents as chloroform, acetoneand propan-2-ol. The slope in the Soczewinski equation for the investigated compounds satisfactorily correlates with the area occupied by the adsorbed solute molecule in the stationary phase.
\end{abstract}

Keywords - thin-layer chromatography, derivatives of 1,4-naphthoquinone, eluent composition, Soczewinski equation, area of solute molecule.

\section{Introduction}

Amino derivatives of 1,4-naphthoquinone exhibit certain types of biological activity, in particular antibacterial, antifungal, as well as chelating activity for the transport of trace elements due to the presence in the structure of the quinone fragment and the corresponding substituents. The modification of chloro derivatives of 1,4-naphthoquinone by amine-containing compounds uses the nucleophilic substitution of chlorine atoms on the R-amine fragment. Synthesis and study of biological activity of derivatives of 1,4-naphthoquinone continue. In particular, antitumor activity of various derivatives of 1,4-naphthoquinone is investigated [1]. Although many works that deal with the synthesis of 1,4-naphthoquinone derivatives, have been reported to use thin-layer chromatography (TLC) to control the completion of the reaction, but the conditions for TLC and separation results are not given. In papers [2,3] the effect of the composition of the eluent on containment on a number of amino acid and cyclic derivatives of 1,4-naphthoquinone under conditions of TLC was investigated.

The purpose of this work is to investigate the chromatographic behavior of six derivatives of 1,4-naphthoquinone by means of normal-phase TLC, as well as to establish the relationship between the retention and structure of these compounds.

\section{Experimental}

In Table 1, the structures are presented for investigated derivatives of 1,4-naphthoquinone I-VI which were synthesized at the Department of Technology of Biologically Active Compounds, Pharmacy and Biotechnology of the National University "Lviv Polytechnic" using the mentioned above reaction and provided for research by the TLC method.

For compounds I-VI as the investigated derivatives of 1,4-naphthoquinone Table 1 also shows the relative area As, calculated according to the monograph [4]. Relative area $A_{s}$ is occupied by one molecule of compound that is adsorbed on the surface of the stationary phase. The measurement unit of the calculated area (AS) corresponds to 8.5 square Ångström, for example, for the benzene ring is taken $\mathrm{A}_{\mathrm{S}}=6$ or 51 square Ångström.

TLC was performed using Silufol plates (manufacturer Kavalier) with broad-pores silica gel named as Silpearl. The solutions concentration of solutes in dimethylsulfoxide (DMSO) was $2-5 \mathrm{mg} / \mathrm{ml}$, and the volume of the solution applied to the starting line was $1 \mu \mathrm{l}$. The solvents used in this work were chosen according to Snyder's classification [4]. In all binary systems, benzene formed the basis, and the elution ability was increased using polar components (chloroform, acetone, acetonitrile, methanol, propan-2-ol) in the range of 2.5 to $10 \%$ vol. Chromatograms were obtained by the method of movement of the solvent from the bottom to the top. Since the 
studied derivatives of 1,4-naphthoquinone were intensively colored, the developing reagents were not used. After air drying, the chromatograms were scanned using a flatbed scanner. The Densitan software was used to process digital imaging in bitmap format. The scanning was performed at a resolution of $600 \mathrm{dpi}$. The distance from the starting line $(\mathrm{L}, \mathrm{mm})$ was calculated by the formula $\mathrm{L}=(\mathrm{N}-1)^{*} \Delta \mathrm{L}$, where $\mathrm{N}$ is the number of measurement points using the Densitan software; $\Delta \mathrm{L}=42 \mu \mathrm{m}$ - the distance between two measuring points according to the scanning resolution.

Table 1

The structures of the 1,4-naphthoquinone derivatives and the area (As) taken by the adsorbed solute molecule on a stationary phase ( $\mathrm{A}_{S}$ is calculated in accordance with [4])

$\left.\begin{array}{c}\text { Number } \\ \text { of } \\ \text { compound }\end{array}\right)$
compound
of

To ensure reproductive experimental conditions and to obtain reliable retention characteristics, such parameters of TLC were maintained constant: the size of the plate, the distance from the starting line from the bottom of $1.0 \mathrm{~cm}$, the amount of solute applied to the starting line, the amount of solvent in the chamber, the time of equilibration of the eluent vapor, the chromatography temperature. For each combination of "solute-eluent with a given 
composition", five chromatograms were obtained and for the subsequent generalizations, the averaged values of $R_{f}$ were used. The standard deviations for the obtained $R_{f}$ values do not exceed 0.015 .

The retention parameter of the compounds were $R_{f}$ and $R_{M}$. The relative retation $\left(R_{f}\right)$ in TLC is calculated by the formula (1) as the ratio of the retention distance of the solute (L) to the distance that passed the front of the mobile phase $\left(\mathrm{L}_{0}=120 \mathrm{~mm}\right)$. The parameter $\mathrm{R}_{\mathrm{M}}($ BateSmith-Westal) was calculated by the formula (2).

$$
\begin{gathered}
\mathrm{R}_{\mathrm{f}}=\frac{\mathrm{L}}{\mathrm{L}_{0}} \\
\mathrm{R}_{\mathrm{M}}=\lg \left(\frac{1}{\mathrm{R}_{\mathrm{f}}}-1\right) .
\end{gathered}
$$

The generalization of the results of TLC was carried out according to the equation (3) proposed by Soczewinski and based on the concept of competition between solvent molecules of a mobile phase and solute molecules for active adsorption centers on the surface of a stationary phase:

$$
\mathrm{R}_{\mathrm{M}}=\mathrm{A}-\mathrm{B} \cdot \lg \left(\mathrm{N}_{\mathrm{B}}\right),
$$

where $\mathrm{N}_{\mathrm{B}}$ - mole fraction of the polar component in the binary mixture of the mobile phase; A and B are constants whose values depend on the properties of the solute and the mobile phase composition. Mathematical data processing was performed using the MS EXEL table processor.

\section{Results and discussion}

Table 2 shows the $R_{\mathrm{f}}$ values for derivatives of 1,4-naphthoquinone. In Fig. 1 there are examples of dependences of the $R_{f}$ values on the volume fraction of the polar component in the eluent. From Fig. 1 it can be seen that the $R_{\mathrm{f}}$ values increase naturally with increasing content of the polar component and within the limits of one compound for an equal volume fraction of the polar component of the mobile phase, the value of $\mathrm{R}_{\mathrm{f}}$ increases in such series: chloroform acetone - propane-2-ol.

The greatest difference in the $\mathrm{R}_{\mathrm{f}}$ values is observed between the investigated substances for all used polar components of the eluent at a concentration of $2.5 \%$ vol., and then with a increase in the content a decrease is observed for this difference and at $10 \%$ vol. all solutes have similar $R_{f}$ values. The sequence of increasing $R_{f}$ for all polar components of the eluent is such that it corresponds to a decrease in the As area occupied by the adsorbed solute molecule in the stationary phase:

\begin{tabular}{|c|c|c|c|c|c|c|}
\hline Number of compound & $(\mathbf{I I I})>$ & $(\mathbf{I})>$ & $(\mathbf{I I}) \approx$ & $(\mathbf{V})>$ & $(\mathbf{V I})>$ & $(\mathbf{I V})$ \\
\hline $\mathrm{A}_{S}=$ & 45.0 & 51.9 & 52.7 & 54.1 & 61.6 & 75.6 \\
\hline
\end{tabular}

By increasing the difference in the Rf values of between the extreme compounds (III) and (IV) in the case of the most favorable for the separation of solutes when the concentration of the polar component of the mobile phase of $2.5 \%$ vol. the following sequence is observed:

\begin{tabular}{|l|c|c|c|}
\hline polar component of the eluent & Chloroform & Acetone & Propane-2-ol \\
\hline$\Delta \mathrm{R}_{\mathrm{f}}$ for compounds (IV) and (VII) & 0.171 & 0.184 & 0.190 \\
\hline
\end{tabular}


Table 2

Relative retention $\left(\mathrm{R}_{\mathrm{f}}\right)$ for compounds I-VI depending on the composition of the binary eluent

\begin{tabular}{|c|c|c|c|c|}
\hline $\begin{array}{l}\text { Number of } \\
\text { compound }\end{array}$ & $\begin{array}{l}\text { Volume fraction of } \\
\text { the polar component } \\
\text { in the eluent, \% vol. }\end{array}$ & Chloroform & Propane-2-ol & Acetone \\
\hline \multirow{4}{*}{ I } & 2.5 & 0.198 & 0.251 & 0.233 \\
\hline & 5.0 & 0.319 & 0.410 & 0.386 \\
\hline & 7.5 & 0.421 & 0.499 & 0.468 \\
\hline & 10.0 & 0.489 & 0.568 & 0.546 \\
\hline \multirow{4}{*}{ II } & 2.5 & 0.172 & 0.219 & 0.209 \\
\hline & 5.0 & 0.307 & 0.370 & 0.353 \\
\hline & 7.5 & 0.412 & 0.472 & 0.465 \\
\hline & 10.0 & 0.487 & 0.566 & 0.544 \\
\hline \multirow{4}{*}{ III } & 2.5 & 0.246 & 0.295 & 0.282 \\
\hline & 5.0 & 0.366 & 0.428 & 0.419 \\
\hline & 7.5 & 0.441 & 0.501 & 0.488 \\
\hline & 10.0 & 0.510 & 0.572 & 0.556 \\
\hline \multirow{4}{*}{ IV } & 2.5 & 0.075 & 0.105 & 0.098 \\
\hline & 5.0 & 0.199 & 0.299 & 0.280 \\
\hline & 7.5 & 0.335 & 0.445 & 0.419 \\
\hline & 10.0 & 0.460 & 0.547 & 0.528 \\
\hline \multirow{4}{*}{ V } & 2.5 & 0.158 & 0.205 & 0.192 \\
\hline & 5.0 & 0.301 & 0.368 & 0.348 \\
\hline & 7.5 & 0.406 & 0.470 & 0.459 \\
\hline & 10.0 & 0.480 & 0.562 & 0.533 \\
\hline \multirow{4}{*}{ VI } & 2.5 & 0.126 & 0.168 & 0.160 \\
\hline & 5.0 & 0.263 & 0.341 & 0.313 \\
\hline & 7.5 & 0.387 & 0.452 & 0.453 \\
\hline & 10.0 & 0.463 & 0.555 & 0.530 \\
\hline
\end{tabular}

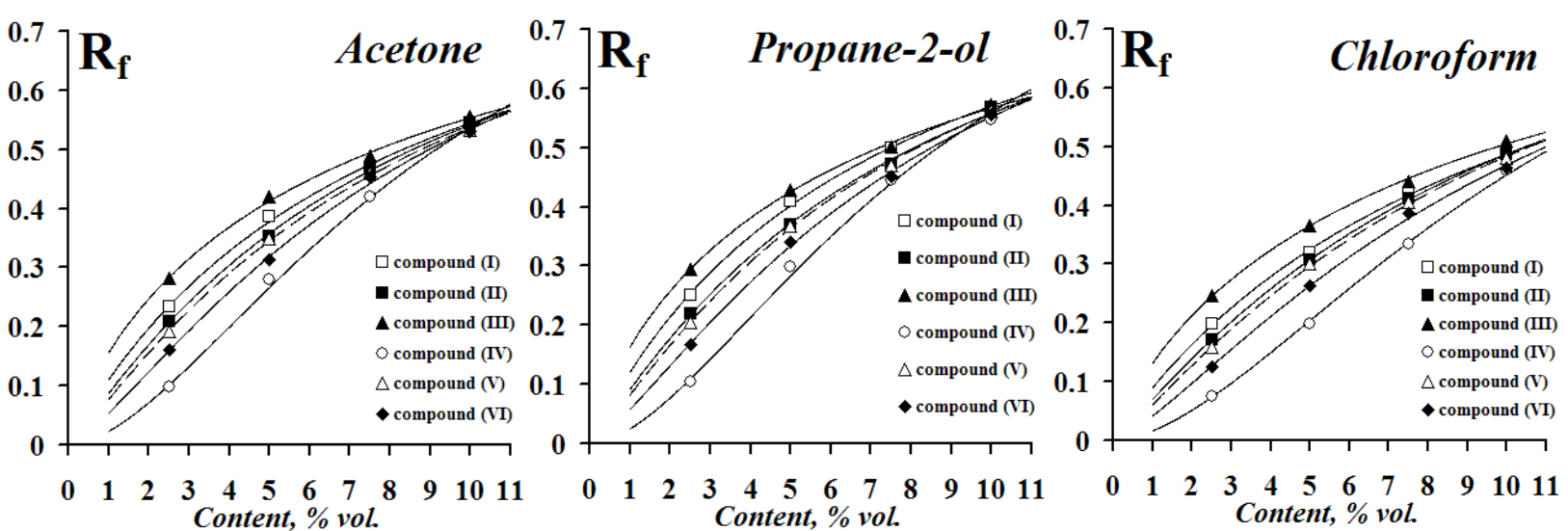

Fig.1. Retention dependencies (Rf) from the content (\% vol.) of the polar component in the eluent for the compounds I to VI

Table 3 shows the parameters $\mathrm{A}$ and $\mathrm{B}$ of the correlations according to the Soczewinski equation (3). If the mobile phase consists only of the polar component, that is, when $\mathrm{N}_{B}=1$, then the constant $\mathrm{A}$ in equation (3) corresponds to the value of $\mathrm{R}_{\mathrm{M}}$. For this limiting case, using the 
constant $A$, the value of $R_{f}\left(N_{B}=1\right)$ is calculated and given in Table 3. The values of $R_{f}\left(N_{B}=1\right)$ naturally approach to one and take place in the range from 0.865 to 0.981 .

Table 3

Parameters A and B of correlations according to Soczewinski equation $R_{M}=A-B \cdot \lg \left(N_{B}\right)$ for the corresponding range of molar part of the polar component in the mobile phase

\begin{tabular}{|c|c|c|c|c|}
\hline $\begin{array}{l}\text { Number of } \\
\text { compound }\end{array}$ & $\begin{array}{c}\text { Parameters of } \\
\text { correlations }\end{array}$ & $\begin{array}{c}\text { Chloroform } \\
\mathrm{N}_{\mathrm{B}}=0,027-0,109\end{array}$ & $\begin{array}{c}\text { Propane-2-ol } \\
\mathrm{N}_{\mathrm{B}}=0,029-0,114\end{array}$ & $\begin{array}{c}\text { Acetone } \\
\mathrm{N}_{\mathrm{B}}=0,030-0,118\end{array}$ \\
\hline \multirow{4}{*}{ I } & A & -0.9258 & -1.0568 & -0.9963 \\
\hline & B & 0.9870 & 0.9921 & 0.9921 \\
\hline & $\mathrm{R}^{2}$ & 0.9989 & 0.9987 & 0.9981 \\
\hline & $\mathrm{R}_{\mathrm{f}}\left(\mathrm{N}_{\mathrm{B}}=1\right)$ & 0.894 & 0.919 & 0.908 \\
\hline \multirow{4}{*}{ II } & $\mathrm{A}$ & -1.0389 & -1.1409 & -1.0919 \\
\hline & $\mathrm{B}$ & 1.1045 & 1.1045 & 1.1010 \\
\hline & $\mathrm{R}^{2}$ & 0.9996 & 0.9982 & 0.9995 \\
\hline & $\mathrm{R}_{\mathrm{f}}\left(\mathrm{N}_{\mathrm{B}}=1\right)$ & 0.916 & 0.933 & 0.925 \\
\hline \multirow{4}{*}{ III } & $\mathrm{A}$ & -0.8073 & -0.9004 & -0.8656 \\
\hline & $\mathrm{B}$ & 0.8311 & 0.8321 & 0.8339 \\
\hline & $\mathrm{R}^{2}$ & 0.9987 & 0.9981 & 0.9978 \\
\hline & $\mathrm{R}_{\mathrm{f}}\left(\mathrm{N}_{\mathrm{B}}=1\right)$ & 0.865 & 0.888 & 0.880 \\
\hline \multirow{4}{*}{ IV } & $\mathrm{A}$ & -1.5486 & -1.7101 & -1.6416 \\
\hline & $\mathrm{B}$ & 1.6988 & 1.7058 & 1.7032 \\
\hline & $\mathrm{R}^{2}$ & 0.9991 & 0.9966 & 0.9976 \\
\hline & $\mathrm{R}_{\mathrm{f}}\left(\mathrm{N}_{\mathrm{B}}=1\right)$ & 0.973 & 0.981 & 0.978 \\
\hline \multirow{4}{*}{ V } & $\mathrm{A}$ & -1.0861 & -1.1899 & -1.1290 \\
\hline & B & 1.1597 & 1.1561 & 1.1505 \\
\hline & $\mathrm{R}^{2}$ & 0.9994 & 0.9991 & 0.9996 \\
\hline & $\mathrm{R}_{\mathrm{f}}\left(\mathrm{N}_{\mathrm{B}}=1\right)$ & 0.924 & 0.939 & 0.931 \\
\hline \multirow{4}{*}{ VI } & $\mathrm{A}$ & -1.2058 & -1.3258 & -1.2787 \\
\hline & $\mathrm{B}$ & 1.3117 & 1.3118 & 1.3157 \\
\hline & $\mathrm{R}^{2}$ & 0.9991 & 0.9989 & 0.9983 \\
\hline & $\mathrm{R}_{\mathrm{f}}\left(\mathrm{N}_{\mathrm{B}}=1\right)$ & 0.941 & 0.955 & 0.950 \\
\hline
\end{tabular}

In all cases, according to Table 3, good correlations are obtained, since the values of R2 are in the range of 0.997 to 0.999 . Constant $\mathrm{A}$ has negative values, their absolute values lie in the range from 0.807 to 1.710 and depend on both the solute and the polar component of the mobile phase. The values of $\mathrm{B}$ lie in the range from 0,8311 to 1,7058 and are appreciably dependent on solute, and also almost do not change from the qualitative composition of the eluent, as evidenced by the data given in Table 3 . The correlation between the mean values of inclination $\mathrm{B}$ and the areas of AS occupied adsorbed molecules of compounds I-VI on the stationary phase is shown in Fig. 2. With an increase in the area of AS an increase in the slope B is observed, which is well in agreement with the theory of retention in the normal phase chromatography, which is described in detail in the monograph [4]. In Fig. 3 shows the relationship between the values of the slopes B and the intercepts $\mathrm{A}$ in Soczewinski equation for the polar components of the mobile phase and compounds I-VI. Value in Fig. 3 within each polar component of the mobile phase are well described by straight lines with close slopes. 


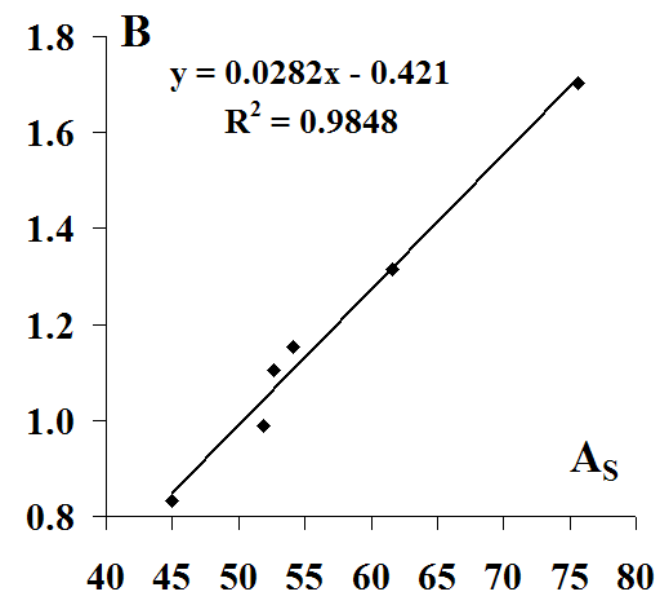

Fig.2. The correlation between the mean values of slopes $B$ and $A_{S}$ areas occupied by adsorbed molecules of compounds I-VI on a stationary phase.

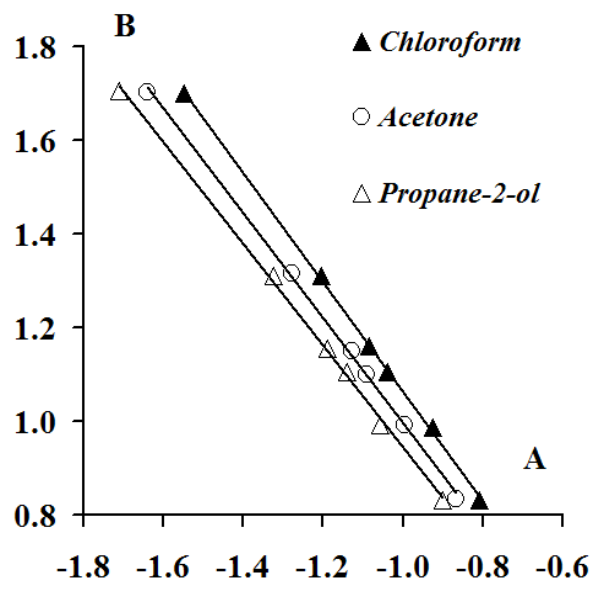

Fig.3. The relationship between the values of the slopes B and the intercepts A in the Soczewinski equation for the polar components of the mobile phase and compounds I-VI.

\section{Conclusion}

The retention of six derivatives of 1,4-naphthoquinone, compounds I-VI under conditions of normal-phase TLC with silica gel, as a stationary phase, and benzene binary elutes with a volume fraction of the corresponding polar components within the range of $2.5-10 \%$ vol. When using the volumetric particle (\%), as the coordinates of the abscissa axis, for all compounds I-VI, the growth of $\mathrm{R}_{\mathrm{f}}$ values is determined for the replacement of the polar component of the mobile phase in the following series: chloroform - acetone - propane-2-ol.

It is shown that the slopes of rectilinear dependences in accordance with the Soczewinski equation between the $\mathrm{R}_{\mathrm{M}}$ values as retention parameter and the logarithm of the molar part of the polar modifier $\lg \left(\mathrm{N}_{\mathrm{B}}\right)$ is well correlated with the area $\left(\mathrm{A}_{\mathrm{S}}\right)$ occupied by the adsorbed molecule of solute on a stationary phase, which was calculated by the Snyder algorithm. For eluents with a certain polar component, the linear correlations were found between the intercepts and slopes in the Soczewinski equation.

It is shown that the largest difference in the $\mathrm{R}_{\mathrm{f}}$ values between the investigated substances is observed for all used polar eluent components at a concentration of $2.5 \%$ vol., that is, the maximum separation is achieved for the investigated compounds of I-VI by TLC method. With increasing content of the polar component in the eluent, there is a decrease in this difference and at $10 \%$ vol. all solutes have almost the same values of $\mathrm{R}_{\mathrm{f}}$.

\section{References}

[1] D. Bhasin, S.N. Chettiar, J.P. Etter, P. Li, M. Mok "Anticancer activity and SAR studies of substituted 1,4-naphthoquinones”, Bioorgan. Med. Chem., 2013, vol. 21, pp. 4662-4669.

[2] O.Ya. Smirnova, I.P. Polyuzhyn, Yo.Yo. Yatchyshyn "Normal phase thin layer chromatography for cyclic derivatives of 3-chloro-1,4-naphthoquinone", Visnyk Lviv. Polytech. Nats. Univ., 2018, vol. 886, pp. 14-22.

[3] O.Ya. Smirnova, I.P. Polyuzhyn, Yo.Yo. Yatchyshyn "Relations between the structure of amino acid derivatives of 3-chloro-1,4-naphthoquinone and their retention in normal-phase thin-layer chromatography", Voprosy khimii i khimicheskoi tekhnologii, 2018, vol. 119, iss 4, pp. 59-68.

[4] L.R. Snyder, "Principles of adsorption chromatography”, New York: Dekker, 1968, 413 p. 